\title{
A Case of Isolated Focal Cerebellar Heterotopia in a Patient Affected by HHT: MR and MR Spectroscopy Findings
}

\author{
Andrea Salvati ${ }^{1 *}$, Franca Dicuonzo ${ }^{1}$, Aristide Carella ${ }^{1}$ and Roberto De Blasi ${ }^{2}$ \\ ${ }^{1}$ Department of Neurological and Psychiatric Sciences, Unit of Neuroradiology, University of Bari, Italy \\ ${ }^{2}$ Unit of Neuroradiology and Interventional Radiology, "Di Venere" Hospital, Italy
}

\begin{abstract}
We describe the MR study of an isolated cerebellar heterotopia , incidentally found in a 17 year-old girl affected by hereditary hemorrhagic teleangectasia. Conventional MR, DWI and MR spectroscopy findings are described; at the best of our knowledge, spectroscopic findings have not been previously reported in this setting. A possible relation between a microvascular damage due to $\mathrm{HHT}$ and the cerebellar malformation is hypotised.
\end{abstract}

Keywords: Cerebellar heterotopia; MR spectroscopy; Hereditary hemorragic teleangectasia; Cortical migration disorder; Congenital malformation; MRI

\section{Introduction}

A practical imaging-based classification of cerebellar malformations distinguishes between focal and diffuse conditions, and between cerebellar hypoplasias and cerebellar dysplasias [1]; among the latter, an important subgroup is represented by cerebellar cortical dysplasias (CCD). CCD has been reported in association with chromosomal abnormalities, congenital muscular dystrophies, other supratentorial brain anomalies, various intrauterine pathologic events (such as infections, toxins or hypoxia); however, its embryogenesis and clinical significance remain poorly understood [2]. Most relevant MR findings of CCD may consist of defective, large, or vertical abnormal fissures; of irregular gray-white matter junction; of lack of normal arborisation of the white matter; of heterotopias in the hemispheric white matter. Cases of major CCD are uncommon in absence of other brain anomalies; on the other hand, focal isolated cerebellar heterotopias are often incidentally diagnosed in asymptomatic patients undergoing MR scan for various indications, and while they may represent a minimal form of $C C D$, their pathologic significance remains unknown [3].

\section{Case Report}

A 17 year-old girl affected by HHT (presenting with epistaxis and diagnosed with the Eng1 mutation) underwent a brain MR for screening purposes; at the time of examination she complained of mild frontal headaches. Conventional sequences showed a small nodular lesion in the left cerebellar hemispheric white matter, involving the dentate nucleus: the lesion always had the same signal intensity of the normal cerebellar cortex, and no mass effect or contrast enhancement were evident. No other brain anomalies were detected and no AVM or other disease-specific alterations were noted at MR angiography and conventional sequences. No alteration suggestive of a major CCD was noted at a high-resolution T1-weighted sequence; no signal alteration was observed at GRE T2* and at DWI. 1(H) MRS was performed with the VOI placed over the lesion and a short TE (35 ms), and displayed a reduced $\mathrm{Naa} / \mathrm{Cr}$ ratio $(1,08)$, with a slightly decreased Cho/Cr ratio $(1,10)$.

\section{Discussion}

CCD include a variety of malformative conditions, ranging from diffuse and extensive to focal and minimal forms [1]. Diagnosis of these alterations is of critical importance, due to the known existence of syndromic CCDs (such as in cases of congenital muscular dystrophies) and to the frequent association with widespread brain anomalies and clinical symptoms (mostly global or motor developmental delay, mental retard and hypotonia [4].

Focal cerebellar heterotopias are a common incidental MR finding, and many consider them a normal variant. Rorke et al. [5] reported pathological findings with the features of cerebellar heterotopias in a very high percentage of newborns without other macroscopic anomalies; however, this condition may be less frequent in older individuals since the development of the cerebellar cortex continues through the first year of extrauterine life.

Recently, a genetic and developmental classification of cerebellar malformations has been outlined [6]; nonetheless, there still persist several conditions whose pathophysiology is object of debate, among which disorders of cerebellar foliation, which include cerebellar heterotopias according to this classification. While a genetic disorder of the cortical migration will explain most of major CCD, minor and isolated anomalies are seemingly caused by different prenatal cerebellar insults, such as infections or focal ischemia [2,7].

Results of MR spectroscopy have not been previously reported in cerebellar heterotopias, while several Authors have described the application of this technique in the study of supratentorial heterotopias, with somehow divergent results. Widjaja et al. [8] have found very similar metabolic patterns in cerebral heterotopias and the white matter of control subjects, and conclude that the neurons and glia in these lesions are mature; Simone et al. [9] and Leite et al. $[10]$ have reported a decreased $\mathrm{Naa} / \mathrm{Cr}$ both in heterotopias and in the normal-appearing contralateral side, compared to a control group, and have suggested the existence of metabolic abnormalities extending over the limits of the lesions. On the other hand, Woermann et al. [11] have reported heterogeneous metabolic variations, with decreased or increased Naa, both in the lesional area and in the perilesional tissue.

*Corresponding author: Dr. Andrea Salvati, Department of Neurological and Psychiatric Sciences, Unit of Neuroradiology, University of Bari, Italy, Tel: 00390805592071; E-mail: salvati andrea@hotmail.com

Received September 06, 2010; Accepted December 28, 2010; Published December 30, 2010

Citation: Salvati A, Dicuonzo F, CarellaA, De Blasi R (2010)A Case of Isolated Foca Cerebellar Heterotopia in a Patient Affected by HHT: MR and MR Spectroscopy Findings. J Neurol Neurophysiol 1:107. doi:10.4172/2155-9562.1000107

Copyright: ( $\odot 2010$ Salvati A, et al. This is an open-access article distributed unde the terms of the Creative Commons Attribution License, which permits unrestricted use, distribution, and reproduction in any medium, provided the original author and source are credited. 


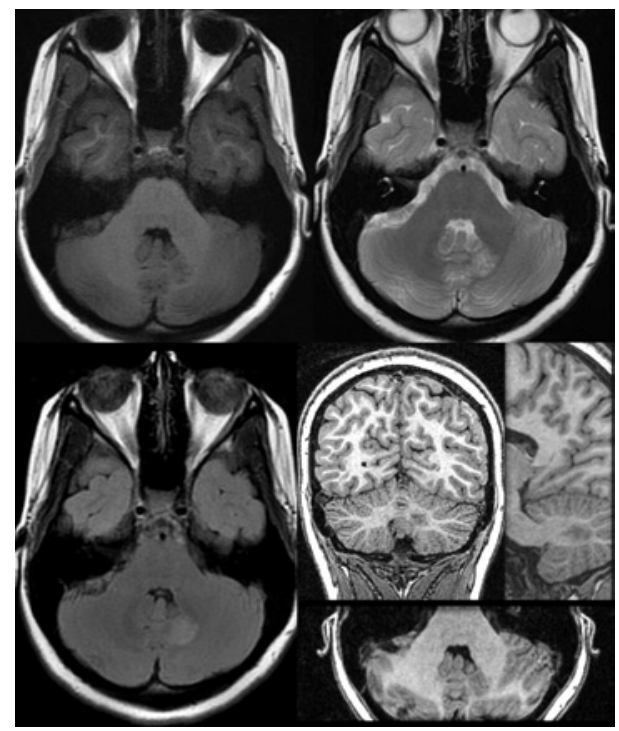

Figure 1: T1-weighted SE, T2-weighted FSE, and FLAIR sequences show a small nodule in the left cerebellar hemispheric white matter, involving the dentate nucleus, with the same signal intensity of the normal cerebellar cortex. T1-weighted high resolution GRE sequence acquired on the coronal plane with sagittal and axial reconstructions confirms the finding and show a normal cerebellar cortex in both hemispheres without signs of dysplasia. A slight hypoplasia of the left cerebellar tonsil is noted.

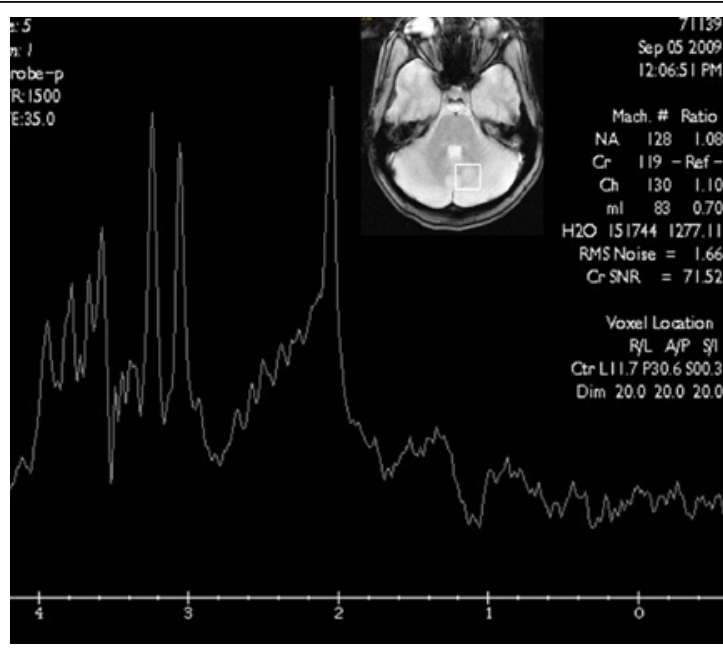

Figure 2: Short (35 ms) TE spectroscopy with VOI located over the lesion shows a decreased $\mathrm{Naa} / \mathrm{Cr}$ ratio $(1,08)$.

In our patient the only spectroscopic anomaly was a decreased Naa/ $\mathrm{Cr}$ ratio in the lesion, which indicates neuronal loss or dysfunction; ratios were compared to accepted normal values on cerebellar tissue [12]. However, we did not perform any spectroscopic measure on the normal appearing cerebellar tissue.

Our hypothesis is that a microscopic alteration of vascular structures related to HHT may have played a role in the determination of the cerebellar heterotopia, disturbing the complex intrauterine processes of cerebellar cortical development. A similar pathophysiological association has been described in patients with disorders of cerebral cortical migration and brain lesions resulting from intrauterine brain ischemia or hypoperfusion $[13,14]$. Such observations are paralleled by those of Pascual-Castroviejo et al. [15], who described a syndrome with facial hemangiomas, intracranial vascular abnormalities and cortical organization disorders, suggesting a direct relation between these features. The evidence of the close interaction between the developing circulatory and nervous system [16], and the demonstration of the existence of a "vascular niche", acting as a permissive substrate and guiding neuronal migration during cerebral cortical development [17], further support such theories. A high expression of the vascular endothelial growth factor and its high-affinity receptor in the human forebrain and cerebellum during the intrauterine gestation has been recently observed [18]; these data suggest that vascular structures are involved in the development of human brain, and likely in processes of cerebral and cerebellar cortical formation. Moreover, the role of hypoxia in determining cerebellar dysplasias during early phases of gestation has been demonstrated in animal models [19].

In conclusion, while the finding of a cerebellar heterotopia in a patient with HHT may be coincidental, it could be hypotized that the inherited microvascular abnormalities of HHT may act as predisposing factors for the development of cerebellar heterotopias, through alterations of complex intrauterine interactions between the developing brain vessels and the migrating cerebellar neurons. This issue may have several important implications in the diagnostic and therapeutic management of patients with HHT.

\section{References}

1. Patel S, Barkovich AJ (2002) Analysis and classification of cerebellar malformations. AJNR Am J Neuroradiol 23: 1074-1087.

2. Soto-Ares G, Devisme L, Jorriot S, Deries B, Pruvo JP, et al. (2002) Neuropathologic and MR imaging correlation in a neonatal case of cerebellar cortical dysplasia. AJNR Am J Neuroradiol 23: 1101-1104.

3. Soto-Ares G (2003) Analysis and classification of cerebellar malformations. AJNR Am J Neuroradiol 24: 153.

4. Soto-Ares G, Delmaire C, Deries B, Vallee L, Pruvo JP (2000) Cerebella cortical dysplasia: MR findings in a complex entity. AJNR Am J Neuroradiol 21: 1511-1519.

5. Rorke LB, Fogelson MH, Riggs HE (1968) Cerebellar heterotopia in infancy. Dev Med Child Neurol 10: 644-650.

6. Barkovich AJ, Millen KJ, Dobyns WB (2009) A developmental and genetic classification for midbrain-hindbrain malformations. Brain 132: 3199-3230.

7. Poretti A, Leventer R, Cowan F, Rutherford MA, Steinlin M, et al. (2008) Cerebellar cleft: a form of prenatal cerebellar disruption. Neuropediatrics 39 106-112.

8. Widjaja E, Griffiths PD, Wilkinson ID (2003) Proton MR spectroscopy of polymicrogyria and heterotopia. AJNR Am J Neuroradiol 24: 2077-2081.

9. Simone IL, Federico F, Tortorella C, De Blasi R, Bellomo R, et al. (1999) Metabolic changes in neuronal migration disorders: evaluation by combined MRI and proton MR spectroscopy. Epilepsia 40: 872-879.

10. Leite CC, Lucato LT, Sato JR, Valente KD, Otaduy MC (2007) Multivoxe proton MR spectroscopy in malformations of cortical development. AJNR Am J Neuroradiol 28: 1071-1075.

11. Woermann FG, McLean MA, Bartlett PA, Barker GJ, Duncan JS (2001) Quantitative short echo time proton magnetic resonance spectroscopic imaging study of malformations of cortical development causing epilepsy. Brain 124 427-436.

12. Safriel Y, Pol-Rodriguez MA, Novotny EJ, Rothman DL, Fulbright RK (2005) Reference values for long echo time MR spectroscopy in healthy adults. AJNR Am J Neuroradiol 26: 1439-1445.

13. Reutens DC, Berkovic SF, Kalnins RM, McKelvie P, Saling MM, et al. (1993) Localised neuronal migration disorder and intractable epilepsy: a prenatal vascular aetiology. J Neurol Neurosurg Psychiatry 56: 314-316.

14. Frater JL, Prayson RA, Morris III HH, Bingaman WE (2000) Surgical pathologic findings of extratemporal-based intractable epilepsy. Arch Pathol Lab Med 124 545-549. 
Citation: Salvati A, Dicuonzo F, Carella A, De Blasi R (2010) A Case of Isolated Focal Cerebellar Heterotopia in a Patient Affected by HHT: MR and MR Spectroscopy Findings. J Neurol Neurophysiol 1:107. doi:10.4172/2155-9562.1000107

Page 3 of 3

15. Pascual-Castroviejo I, Pascual-Pascual SI, Lopez-Gutierrez JC, VelazquezFragua R, Viaño J (2007) Facial hemangioma and hemispheric migration disorder: presentation of 5 patients. AJNR Am J Neuroradiol 28: 1609-1612.

16. Mercier F, Hatton G (2000) Immunocytochemical basis for a meningeoglial network. J Comp Neurol 420: 445-465.

17. Stubbs D, DeProto J, Nie K, Englund C, Mahmud I (2009) Neurovascular congruence during cerebral cortical development. Cereb Cortex 19: i32-i41.
18. Sentilhes L, Michel C, Lecourtois M, Catteau J, Bourgeois P, et al. (2010) Vascular endothelial growth factor and its high-affinity receptor (VEGFR-2) are highly expressed in the human forebrain and cerebellum during development. J Neuropathol Exp Neurol 69: 111-128.

19. Lee C, Kim DW, Jeon GS, Roh EJ, Seo JH, et al. (2001) Cerebellar alterations induced by chronic hypoxia: an immunohistochemical study using a chick embryonic model. Brain Res 901: 271-276. 